\title{
Enhancement of baicalin by hexamethylene bisacetamide on the induction of apoptosis contributes to simultaneous activation of the intrinsic and extrinsic apoptotic pathways in human leukemia cells
}

\author{
XIA REN $^{1 *}$, YUBAO ZHANG ${ }^{2 *}$, CUILING LI $^{1}$, HENGXIAO WANG $^{1}$, ZHENG JIANG $^{3}$, ZHIYONG ZHANG $^{1}$, \\ QIANG GUO $^{1}$, GUANHUA SONG $^{1}, \mathrm{KEHONG} \mathrm{BI}^{4}$ and GUOSHENG JIANG ${ }^{1,5}$

\begin{abstract}
${ }^{1}$ Key Laboratory for Rare and Uncommon Diseases, Key Laboratory for Tumor Immunology and Chinese Medicine Immunology of Shandong Province, Institute of Basic Medicine, Shandong Academy of Medical Sciences;

${ }^{2}$ Department of Neurosurgery, Shandong Provincial Hospital Affiliated to Shandong University; ${ }^{3}$ Department of Neurosurgery, Qilu Hospital of Shandong University; ${ }^{4}$ Department of Hematology, Qianfoshan Hospital, Jinan, Shandong, P.R. China
\end{abstract}

Received April 19, 2013; Accepted June 21, 2013

DOI: $10.3892 /$ or.2013.2684

\begin{abstract}
Hexamethylene bisacetamide (HMBA) and natural flavanoid baicalin both exert potent antileukemic activity. However, there is currently no data on the anti-leukemic effects of baicalin in combination with HMBA. In the present study, we demonstrated that the combination of baicalin and HMBA synergistically inhibited the proliferation of acute myeloid leukemia (AML) cell lines. In addition, a slight $\mathrm{G}_{0} / \mathrm{G}_{1}$ phase arrest and significant apoptosis were observed. The combination treatment triggered apoptosis through the intrinsic pathway, which involved loss of MMP, decreased $\mathrm{Bcl}-2 / \mathrm{Bax}$ ratio and $\mathrm{Bcl}-\mathrm{X}_{\mathrm{L}} / \mathrm{Bax}$ ratio, caspase- 9 activation, as well as through the extrinsic pathway mediated by Fas and caspase- 8 activation. On the other hand, combination of baicalin and HMBA showed little toxic effect on peripheral blood mononuclear cells from healthy volunteers. Our results raise the possibility that the novel combination of baicalin and HMBA may be a promising regimen for the treatment of AML.
\end{abstract}

Correspondence to: Dr Kehong Bi, Department of Hematology, of Qianfoshan Hospital, 85 Jingshi Road, Jinan, Shandong 250014, P.R. China

E-mail: bkh426@163.com

Dr Guosheng Jiang, ${ }^{5}$ Present address: Department of HematoOncology, Institute of Basic Medicine, Shandong Academy of Medical Sciences, 11877 Jingshi Road, Jinan, Shandong 250062, P.R. China

E-mail: jianggsh@hotmail.com

*Contributed equally

Key words: apoptosis, acute myeloid leukemia, synergy, baicalin, hexamethylene bisacetamide

\section{Introduction}

Acute myeloid leukemia (AML) is a hematologic malignancy characterized by a block of terminal differentiation of the hematopoietic progenitors at early stages in myelopoiesis. AML accounts for $25 \%$ of all leukemias diagnosed in adults and its incidence is stably increasing (1). In the past two decades, there has been little improvement in chemotherapeutic regimens and hence the overall survival for patients with AML remains poor, with a 5-year survival rate of $\sim 20 \%(2,3)$ and median survival times of only a few months for elderly patients (4). This is partly due to a higher prevalence of unfavorable cytogenetics and myelodysplasia, a higher incidence of MDR, and more frequent comorbidities that often render them unsuitable for intensive treatment $(4,5)$. Therefore, it is urgent to seek new novel therapeutic agents and strategies with less systemic toxicity for improving the treatment outcomes of elderly patients.

In the past decades, natural products have played a critical role in drug discovery and development. The potential of natural products from plants, notably from traditional Chinese medicine (TCM), has been recognized by the scientific community in the Western world for its low toxicity, and considerable efforts have been made to systematically investigate the active component of TCM for cancer therapy. A series of natural products, such as Homoharringtonine (6), arsenic trioxide (ATO) (7) and paclitaxel (8), have been found and clinically proved for their potential use in leukemia therapy. They demonstrate the translation of basic knowledge of purified agents of complex mixtures from TCM into the clinic. In addition, the successful application of combination of all-trans retinoic acid (ATRA) and ATO therapy in APL demonstrates that the combination of TCM with synthesized compound provides an attractive strategy for the development of novel and improved cancer therapeutics $(9,10)$.

We have focused on studies of TCM treatment in leukemia for decades and have tested more than 10 chemically charac- 
terized compounds from TCM treatment in leukemia cell lines and found several active compounds such as icariin (11) and baicalin (12). Baicalin is a flavonoid compound isolated from Scutellaria baicalensis, a Chinese traditional medicinal herb widely used as an anti-inflammatory (13), antibacterial, anxiolytic and hepatoprotective drug (14). Accumulating evidence demonstrates that baicalin exhibits potent antitumor properties by suppressing cell growth, modulating cell cycle, inducing differentiation or apoptosis in leukemia cell lines $(15,16)$, without affecting primary or normal cells $(17,18)$, raising the possibility of treating even older patients with AML.

Hexamethylene bisacetamide (HMBA), a hybrid polar compound, was used in phase I and II clinical trials for the treatment of myelodysplastic syndrome (MDS) and AML (19). Previous studies demonstrated that HMBA exerted dose-dependent dual effects on AML cells. At low concentrations, HMBA induces terminal differentiation in a variety of leukemic cell lines $(20,21)$, while it inhibits cell growth significantly at high concentrations through apoptosis and cell cycle delay rather than through differentiation. Evidence indicates that HMBA induced apoptosis associated with downregulation of Bcl-2 gene expression, upregulation of expression of p21, p53 (22), or HMBA induced the activation of a caspase-independent cell death pathway (23). Additionally, other studies documented that HMBA can be efficacious as an adjunct agent for enhancing the antitumor effects of antineoplastic drugs $(24,25)$. However, some serious side-effects were induced when administered at higher concentrations, such as thrombocytopenia, thereby limiting the utilization of this agent in cancer chemoprevention (21).

It was previously reported that suberoylanilide hydroxamic acid (SAHA) and flavopiridol (FP) interact synergistically to induce mitochondrial damage and apoptosis in human leukemia cells $(26,27)$. In view of the similar molecular structure between SAHA and HMBA, and that between FP and baicalin, together with their potential antileukemic efficacy, the enhancement of baicalin by HMBA in growth arrest and apoptosis induction of AML cells in the present study were detected and the underlying mechanism of their effect was also elucidated.

\section{Materials and methods}

Reagents. Baicalin with a purity of up to $99.5 \%$ was kindly provided by Professor Xiao Wang (Shandong Analysis and Test Center, Shandong Academy of Sciences) and $10 \mathrm{mg} / \mathrm{ml}$ solution dissolved with DMSO was stored at $-20^{\circ} \mathrm{C}$. HMBA was obtained from Sigma (St. Louis, MO, USA) and 0.5 M stock solution was made by dissolving it in RPMI-1640 medium (Gibco, Grand Island, NY, USA). Propidium iodide (PI), rhodamine 123 (Rh123) were also purchased from Sigma. Hoechst 33342 was obtained from Beyotime Biotechnology, Inc. (Nantong, China). Annexin V fluorescein isothiocyanate (FITC) kit was obtained from BD Biosciences (San Diego, CA, USA). Antibodies for detecting Bax, Bcl-2, cleaved caspase-3, -8, -9, Fas were purchased from Cell Signaling Technology (Beverly, MA, USA). $\beta$-actin antibody was purchased from Santa Cruz Biotechnology, Inc. (Santa Cruz, CA, USA). Horseradish peroxidase-labeled $\mathrm{IgG}$ anti-mouse and anti-rabbit antibodies were supplied by Zhongshan Golden
Bridge Biotechnology Co. (Beijing, China). Cell Counting Kit-8 (CCK-8) was obtained from Dojindo Laboratories (Kumamoto, Japan).

Cell culture. AML cell lines NB4 and THP-1 were purchased from American Type Culture Collection (ATCC, Bethesda, MD, USA); HL-60 cells and K562 cells were conserved by our laboratory. Cells were cultured in RPMI-1640 medium supplemented with $10 \%$ heat-inactivated newborn calf serum (NCS), $100 \mathrm{IU} / \mathrm{ml}$ penicillin and $100 \mathrm{IU} / \mathrm{ml}$ streptomycin at $37^{\circ} \mathrm{C}$ in an atmosphere with $5 \% \mathrm{CO}_{2}$. Logarithmically growing cells were exposed to drugs for the indicated time periods.

Human peripheral blood mononuclear cells (PBMCs) were isolated from heparinized venous blood of healthy volunteers by Ficoll-Paque density gradient centrifugation. After washing with PBS twice, PBMCs were cultured in RPMI-1640 with $10 \% \mathrm{FCS}$ at $37^{\circ} \mathrm{C}$ in a humidified atmosphere containing $5 \%$ $\mathrm{CO}_{2}$. After incubating on a plastic plate for $6 \mathrm{~h}$, non-adherent cells were collected and used for cytotoxicity assay (18).

Cell viability assay. Cellular viability was detected using CCK- 8 according to the manufacturer's instructions. In brief, logarithmically growing cells were seeded on 96-well plates at a density of $1 \times 10^{4}$ cells/well in $100 \mu \mathrm{l}$ of medium in triplicate and treated with baicalin $(5,10,20,40,80 \mu \mathrm{g} / \mathrm{ml})$ or HMBA $(0.5,1,2,4 \mathrm{mM})$ or in combination. Cells treated with $0.1 \%$ (v/v) DMSO or RPMI-1640 medium were used as control. Following incubation for $24 \mathrm{~h}, 10 \mu \mathrm{l}$ of CCK-8 solution was added to each well in the assay plate and incubated for an additional $2 \mathrm{~h}$ at $37^{\circ} \mathrm{C}$. Absorbance was measured at $450 \mathrm{~nm}$ using a microplate reader (Model 550; Bio-Rad, USA). Each group had triplicate samples. The inhibition rate was calculated by the following formula: cell inhibition rate $(\%)=1$ - average absorbance of treated group/average absorbance of control group $\times 100 \%$. Data were calculated as the means \pm SD of triplicate samples and are representative of at least three independent assays.

The cytotoxicity of baicalin and HMBA on PBMCs was assayed by the trypan blue exclusion test. Briefly, PBMCs from two healthy volunteers were cultured with $20 \mu \mathrm{g} / \mathrm{ml}$ baicalin and/or $2 \mathrm{mM}$ HMBA for 3 days, then $1 \mu \mathrm{l}$ of trypan blue dye was added to cell suspension, mixed and incubated for $2 \mathrm{~min}$. Dye-cell suspension was loaded to a counting chamber and counted under a microscope to determine whether cells take up or exclude dye. Percentage of viable cells was calculated by the following formula: $\%$ of viable cells = number of viable cells counted/total number cells counted.

Cell cycle analysis. Following baicalin $(20 \mu \mathrm{g} / \mathrm{ml})$ and/or HMBA ( $2 \mathrm{mM})$ treatment for $24 \mathrm{~h}, \mathrm{HL}-60$ cells $\left(3 \times 10^{5}\right)$ were washed twice with ice-cold PBS, and fixed in cold $75 \%$ ethanol at $4^{\circ} \mathrm{C}$ for at least $24 \mathrm{~h}$. Then the cells were rinsed with PBS, resuspended in $1 \mathrm{ml}$ of cell cycle buffer $(0.38 \mathrm{~mm} \mathrm{Na}$-Citrate, $0.5 \mathrm{mg} / \mathrm{ml}$ RNase A and $20 \mu \mathrm{g} / \mathrm{ml} \mathrm{PI}$ ) at room temperature for $30 \mathrm{~min}$ and analyzed using an EPICS XL flow cytometer with EXPO32 ${ }^{\mathrm{TM}}$ ADC software (Beckman Coulter, Miami, FL, USA).

Morphological assessment of apoptosis. HL-60 cells were plated $\left(3 \times 10^{5}\right.$ cells/well) after baicalin $(20 \mu \mathrm{g} / \mathrm{ml})$ and $/$ or HMBA ( $2 \mathrm{mM}$ ) treatment for $24 \mathrm{~h}$; cell morphology was observed with 
Table I. The sequence of primers, size of products and annealing temperatures for reverse transcription-PCR.

\begin{tabular}{|c|c|c|c|}
\hline Primers & Sequence of primers & $\begin{array}{l}\text { Size of products } \\
\text { (bp) }\end{array}$ & $\begin{array}{l}\text { Annealing temperatures } \\
\qquad\left({ }^{\circ} \mathrm{C}\right)\end{array}$ \\
\hline$\beta$-actin & $\begin{array}{l}\text { Sense: 5'-GTGGGGCGCCCCAGGCAGGCACCA-3' } \\
\text { Antisense: 5'-CTCCTTAATGTCACGCACGATTTC-3' }\end{array}$ & 540 & 55 \\
\hline$\beta$-actin & $\begin{array}{l}\text { Sense: 5'-ACTATGTTTGAGACCTTCAACA-3' } \\
\text { Antisense: 5'-CATCTCTTGCTCGAAGTCCA-3' }\end{array}$ & 318 & 55 \\
\hline $\mathrm{Bcl}-2$ & $\begin{array}{l}\text { Sense: 5'-AGGCACCCAGGGTGATGCAA-3' } \\
\text { Antisense: 5'-GTGGAGGAGCTCTTCAAGGA-3' }\end{array}$ & 304 & 56 \\
\hline Bax & $\begin{array}{l}\text { Sense: 5'- ATGTCAAACGTGCGAGTGTC-3' } \\
\text { Antisense: 5'-TCTGTAGTAGAACTCGGGCAA-3' }\end{array}$ & 289 & 55 \\
\hline Bcl-X ${ }_{L}$ & $\begin{array}{l}\text { Sense: 5'-GGAGCTGGTGGTTGACTTTCT-3' } \\
\text { Antisense: 5'-GTACCGCAGTTCAAACTCGTC-3' }\end{array}$ & 286 & 55 \\
\hline Caspase-9 & $\begin{array}{l}\text { Sense: 5'-CTAGTTTGCCCACACCCAGT-3' } \\
\text { Antisense: 5'-GCATTAGCGACCCTAAGCAG-3' }\end{array}$ & 172 & 55 \\
\hline Caspase- 8 & $\begin{array}{l}\text { Sense: 5'-GGACAGGAATGGAACACACTT-3' } \\
\text { Antisense: 5'-TCAGGATGGTGAGAATATCATC-3' }\end{array}$ & 557 & 50 \\
\hline
\end{tabular}

light microscopy. For nuclear morphology, cells were washed twice with PBS, fixed with $4 \%$ paraformaldehyde for $15 \mathrm{~min}$ and stained with Hoechst $33342(10 \mu \mathrm{g} / \mathrm{ml})$ for $5 \mathrm{~min}$ at room temperature in the dark. After washing three times, cells were resuspended by PBS. Stained nuclei were observed by a Nikon ECLIPSE Ti Fluorescence Microscope (Nikon, Japan) and photographed.

Apoptosis assessment by Annexin V/PI staining. Following drug exposure for $24 \mathrm{~h}, 3 \times 10^{5}$ cells were harvested, washed twice with cold PBS and resuspended in $100 \mu \mathrm{l}$ of $1 \mathrm{X}$ binding buffer containing $5 \mu \mathrm{l}$ Annexin $\mathrm{V}$ and $10 \mu \mathrm{l} \mathrm{PI}$ for $15 \mathrm{~min}$ at room temperature in the dark. Flow cytometry measurements were made on a Beckman Coulter EPICS XL cytometer.

Assays for analysis of mitochondrial membrane potential $\left(\Delta \Psi_{m}\right) . \Delta \Psi \mathrm{m}$ was assessed using fluorescent dye Rh123 and flow cytometric analysis. Briefly, following drug treatments for $6 \mathrm{~h}$, the cells were washed twice with PBS; $1 \times 10^{6}$ cells in different groups were incubated with $10 \mathrm{mg} / \mathrm{ml} \mathrm{Rh} 123$ for $30 \mathrm{~min}$ at $37^{\circ} \mathrm{C}$. Following incubation, cells were washed twice and resuspended in PBS followed by flow cytometric analysis. The change in the mean fluorescence intensity reflects the modification of $\Delta \Psi \mathrm{m}$, which drives the uptake and accumulation of Rh123 in the mitochondria.

Reverse transcription (RT)-PCR analysis. Following baicalin $(20 \mu \mathrm{g} / \mathrm{ml})$ and/or HMBA $(2 \mathrm{mM})$ treatment for $24 \mathrm{~h}, \mathrm{HL}-60$ cells were collected and total RNA was extracted from each sample of $1 \times 10^{6}$ cells by TRIzol (Invitrogen, Carlsbad, CA, USA) according to the manufacturer's protocol. The RNA samples were resuspended in RNase-free water and frozen at $-80^{\circ} \mathrm{C}$ until use. RT-PCR was performed as previously described (28). The PCR products were electrophoresed in $1.5 \%$ agarose gels. The primers used were all synthesized by
Sangon Co., Ltd. (Shanghai, China). The sequences are listed in Table I.

Western blot analysis. After exposing to baicalin $(20 \mu \mathrm{g} / \mathrm{ml})$ and/or HMBA ( $2 \mathrm{mM}$ ) for $24 \mathrm{~h}$, HL-60 cells were washed twice with cold PBS and lysed in extraction buffer $(50 \mathrm{mM}$ Tris- $\mathrm{HCl} \mathrm{pH} 7.4,150 \mathrm{mM} \mathrm{NaCl}, 1 \mathrm{mM}$ PMSF, $1 \mathrm{mM}$ EDTA, $1 \%$ Triton $\mathrm{X}-100,0.5 \%$ deoxycholate, $1 \mu \mathrm{g} / \mathrm{ml}$ leupeptin, $2 \mu \mathrm{g} / \mathrm{ml}$ aprotinin, $1 \mathrm{mM} \mathrm{Na} \mathrm{VO}_{4}$ and $0.1 \% \mathrm{SDS}$ ) for $30 \mathrm{~min}$ on ice. The lysates were centrifuged at $12,000 \mathrm{x} \mathrm{g}$ for $15 \mathrm{~min}$ and quantified using Bradford protein assay. Proteins were separated by SDS-PAGE and electroblotted onto PVDF membranes. The membranes were blocked with $5 \%$ milk for $1 \mathrm{~h}$ and incubated with primary monoclonal antibodies against caspase-8 $(1: 1,000)$, caspase- $9(1: 1,000)$, cleaved caspase-3 $(1: 1,000)$, Fas $(1: 1,000)$, Bcl-2 $(1: 1,000)$ and Bax $(1: 1,000)$ (Cell Signaling Technology) overnight at $4^{\circ} \mathrm{C}$ followed by incubation with HRP-conjugated secondary antibodies (Zhongshan Golden Bridge Biotechnology Co.) for $1 \mathrm{~h}$. The protein bands were visualized using Immobilon Western Chemiluminescent HRP Substrate (Millipore, Billerica, MA, USA) and pictured by LAS-4000 Mini luminescent image analyzer (Fujifilm, Tokyo, Japan).

Statistical analysis. Data presented are the means \pm SD from at least three independent experiments and the significance of difference between two groups was compared by one-way analysis of variance (ANOVA) followed by Tukey's test using SPSS 13.0 (SPSS, Chicago, IL, USA). P<0.05 was considered to indicate statistically significant differences.

\section{Results}

Combined treatment with baicalin and HMBA synergistically inhibits the proliferation of AML cell lines. To determine the 

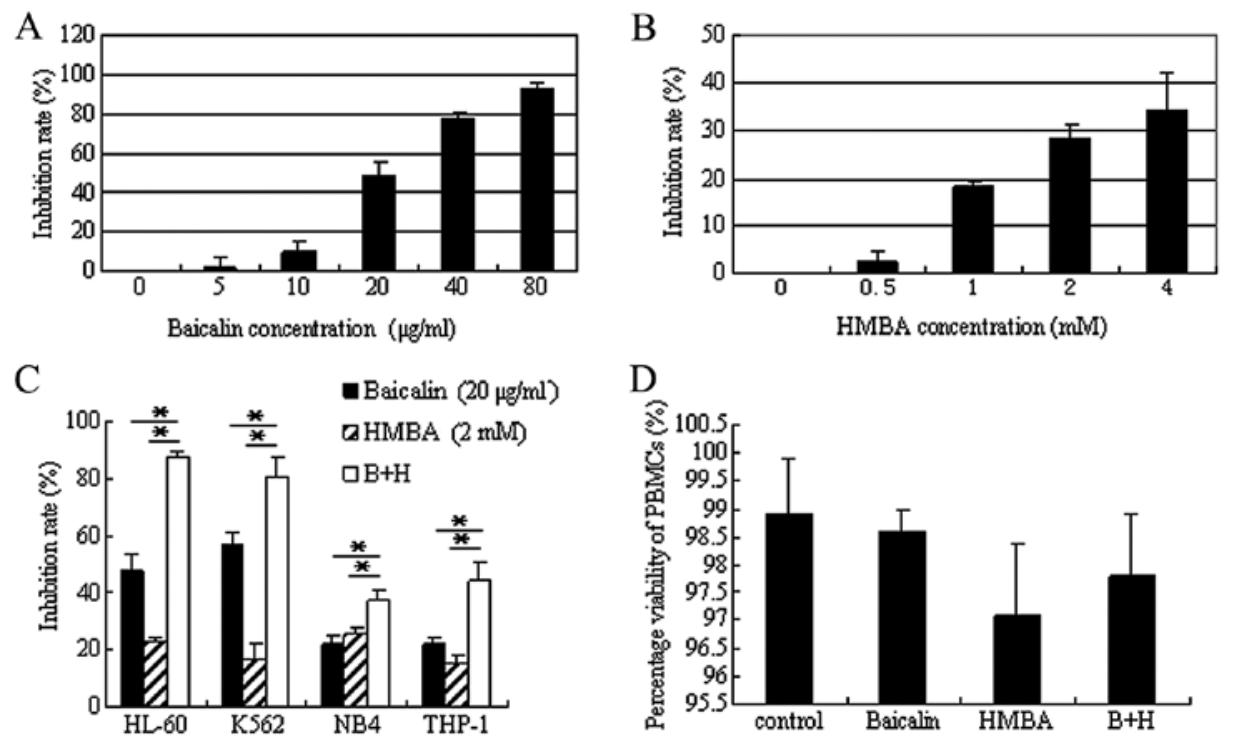

Figure 1. Inhibitory effect of baicalin and hexamethylene bisacetamide (HMBA) alone or in combination on acute myeloid leukemia cell lines. (A and B) HL-60 cells were treated with various concentrations of baicalin $(0,5,10,20,40,80 \mu \mathrm{g} / \mathrm{ml})$ or $\mathrm{HMBA}(0,0.5,1,2,4 \mathrm{mM})$ for $24 \mathrm{~h}$. Cell viability was measured by CCK-8 assay and cell growth inhibition rate were calculated as described in Materials and methods. Values represent the means \pm SD in triplicates in three separate experiments. (C) HL-60, K562, NB4, THP-1 cells were simultaneously exposed to $20 \mu \mathrm{g} / \mathrm{ml}$ baicalin and $2 \mathrm{mM}$ HMBA for $24 \mathrm{~h}$, then cell viability was detected and analyzed as described in (A). (D) Peripheral blood mononuclear cells (PBMCs) from three healthy volunteers were cultured with $20 \mu \mathrm{g} / \mathrm{ml}$ baicalin and/or $2 \mathrm{mM}$ HMBA for 3 days. The cell viability was analyzed by trypan blue exclusion test. Values represent the means \pm SD of three separate experiments. ${ }^{*} \mathrm{P}<0.01$ compared with combination treatment.

optimal combined concentration, HL-60 cells were initially treated with various concentrations of baicalin or HMBA alone. As shown in Fig. 1A, at the indicated concentration scope, baicalin inhibited cell proliferation in a dose-dependent manner. The $\mathrm{IC}_{50}$ value of baicalin was $21.8 \mu \mathrm{g} / \mathrm{ml}$ calculated according to the dose-response curve. At this concentration baicalin showed almost no cytotoxicity in PBMCs even after 5.5 days of culture (18). Therefore, $20 \mu \mathrm{g} / \mathrm{ml}$ was selected for the subsequent analysis. HMBA has been shown to induce differentiation in multiple leukemia types at a concentration of 2-5 mM (29). Thus, the 0-4 mM of HMBA concentration range was selected for cell viability assay. CCK-8 assay indicated that HMBA induced cell growth arrest in a dose-dependent manner, but more mildly than baicalin (Fig. 1B). Based on this growth inhibition of HMBA and the low efficient concentration used in the clinic (30), $2 \mathrm{mM}$ was determined for the combined concentration of HMBA.

Next, studies were performed to detect the inhibitory effect of the combination treatment. Following coadministration of $20 \mu \mathrm{g} / \mathrm{ml}$ baicalin with $2 \mathrm{mM}$ HMBA for $24 \mathrm{~h}$, the inhibition rate strikingly increased from $47.5 \pm 6.3$ or $22.6 \pm 1.5$ to $87.4 \pm 2.6 \%(\mathrm{P}<0.01)$, which indicated that combination treatment exerted a synergistic inhibitory effect on the proliferation of HL-60 cells. To determine whether the synergistic effect was restricted to HL-60 cells, parallel studies were performed in other human leukemia cell lines K562, THP-1 and NB4 and the same results were obtained (Fig. 1C). Of these cell lines, the combination treatment showed the most significant inhibitory effect on HL-60 cells. Therefore the following experiments were performed with HL-60 cells.

In order to confirm that the combination of baicalin and HMBA has selectivity for malignant cells, rather than also indiscriminately killing normal cells, PBMCs were separated from healthy volunteers and cultured with baicalin and/or
HMBA. The trypan blue staining results demonstrated that single agent or combination treatment had only slight cytotoxicity on PBMCs even after 3 days of culture (Fig. 1D).

Combined treatment with baicalin and HMBA induces a slight $G_{0} / G_{l}$ arrest in $H L-60$ cells. To investigate the mechanisms underlying the enhanced growth inhibitory effect of the combination of baicalin and HMBA in HL-60 cells, we performed the cell cycle analysis by flow cytometry. As shown in Fig. 2, no significant changes in cell distribution were observed following exposure of HL-60 cells to $20 \mu \mathrm{g} / \mathrm{ml}$ baicalin or $2 \mathrm{mM}$ HMBA for $24 \mathrm{~h}$, although both cause $\mathrm{G}_{0} / \mathrm{G}_{1}$ phase arrest for $48 \mathrm{~h}$ or longer (data not shown). However, combined treatment with baicalin and HMBA slightly increased the proportion of cells in the $\mathrm{G}_{0} / \mathrm{G}_{1}$ phase from $29.2 \%$ in the vehicle-treated cells to $37.6 \%$ $(\mathrm{P}<0.05)$. The data indicated that a block in the cell cycle may be partly associated with the synergistic inhibitory effect on the proliferation of HL-60 cells after $24 \mathrm{~h}$ combined treatment.

Combination of baicalin and HMBA enhances induction of apoptosis in HL-60 cells. To determine whether the synergistic inhibitory effect on combined treatment of HL-60 cells with baicalin and HMBA was due to the induction of apoptosis, cell morphological changes were observed under a light micrograph and under an inverted fluorescence microscope after Hoechst 33342 staining. It was noted that HMBA-treated cells presented no significant morphological changes but only with the numbers decreased compared to control cells. However, after exposure to $20 \mu \mathrm{g} / \mathrm{ml}$ baicalin for $24 \mathrm{~h}$, the number of HL-60 cells significantly decreased and, also, part of the cells exhibited typical morphological characteristics of apoptosis (such as cell shrinkage, membrane blebbing and formation of apoptotic bodies) (Fig. 3A). Combined with HMBA, the phenomenon became stronger. Accordingly, Hoechst 33342 staining results 
A
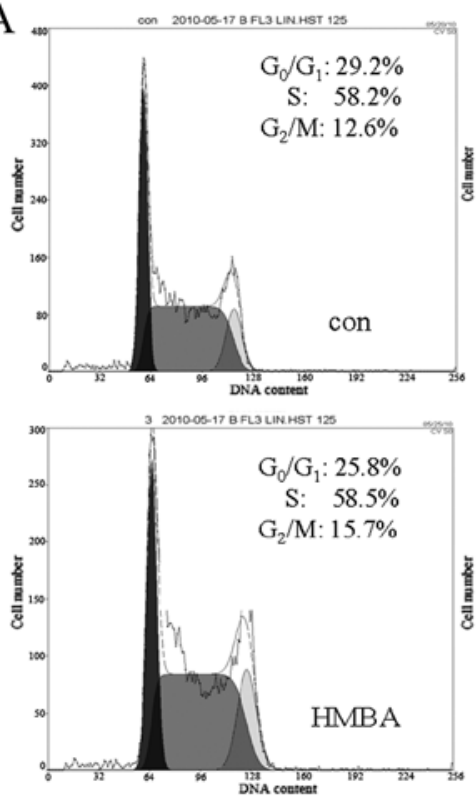
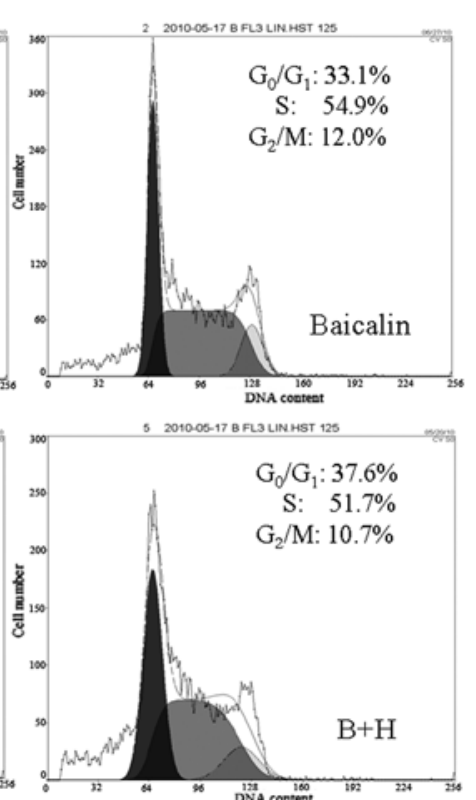

B

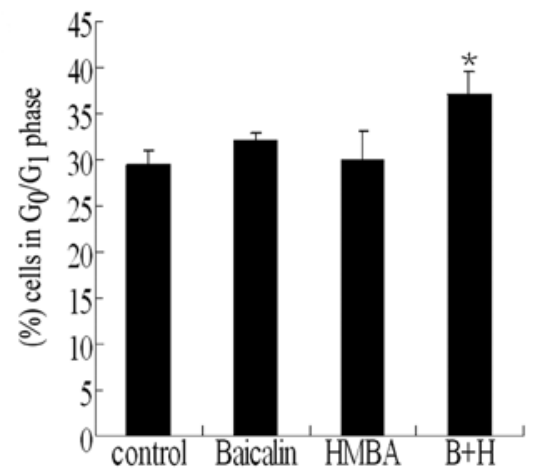

Figure 2. Effect of baicalin and hexamethylene bisacetamide (HMBA) on cell cycle distribution. (A) Following exposure to baicalin (20 $\mu$ g/ml) and/or HMBA $(2 \mathrm{mM})$ for $24 \mathrm{~h}$, HL-60 cells were centrifuged, incubated in $70 \%$ ethanol, stained with propidium iodide, and the DNA content was then analyzed by flow cytometry as described in Materials and methods. (B) Quantitative data from (A). Values represent the means \pm SD of a triplicate experiment. "P<0.05 vs. control.
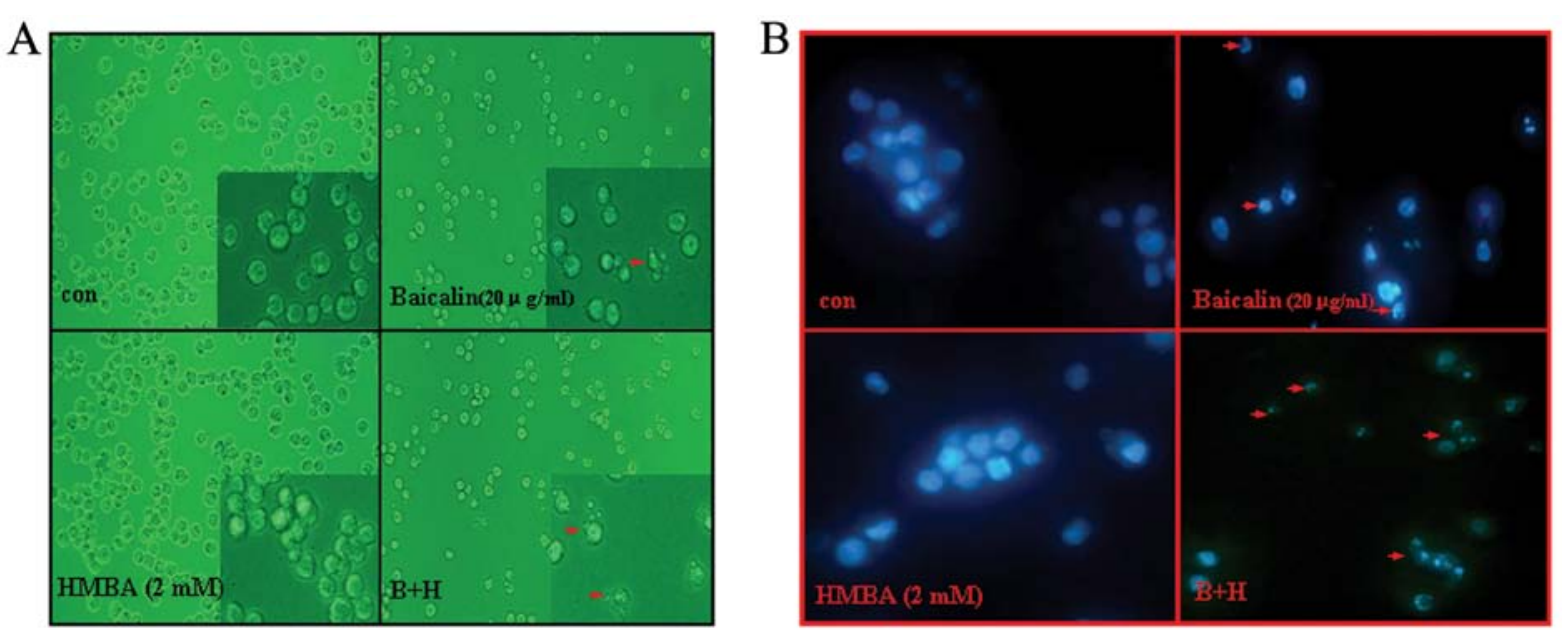

Figure 3. Morphological assessment of apoptosis induced by coadministration with baicalin and hexamethylene bisacetamide (HMBA) in HL-60 cells. Exponentially growing HL-60 cells were exposed to $20 \mu \mathrm{g} / \mathrm{ml}$ baicalin and/or $2 \mathrm{mM}$ HMBA for $24 \mathrm{~h}$. (A) The morphological changes of HL-60 cells were examined by light microscopy. Cell shrinkage and formation of apoptotic bodies were considered as apoptotic cells (x200, x400). (B) Nucleolus morphological changes were observed under fluorescence microscope after Hoechst 33342 staining. Condensed or fragmented nuclei were considered as apoptotic cells (x400). Arrows indicate apoptotic cells.

showed that the nuclei of untreated cells and HMBA-treated cells were round and large in size, exhibiting homogeneous blue fluorescence. By contrast, parts of cells treated with baicalin for $24 \mathrm{~h}$ were observed with condensed or fragmented nuclei which is characteristic of cell apoptosis. Moreover, the apoptosis events in the combination group were more distinguished than in the baicalin treatment group (Fig. 3B).

To further validate the enhanced effect of combined treatment on cell apoptosis, the extent of apoptosis was evaluated by Annexin V/PI assay. As indicated in Fig. 4, cotreatment with $20 \mu \mathrm{g} / \mathrm{ml}$ baicalin and $2 \mathrm{mM}$ HMBA showed a synergistic effect (34\% total apoptotic cells) on the induction of apoptosis in HL-60 cells compared to 24.4 and $7.7 \%$ for
$20 \mu \mathrm{g} / \mathrm{ml}$ baicalin and $2 \mathrm{mM}$ HMBA treatment alone, respectively. These findings suggest that HMBA enhances apoptosis induced by baicalin on HL-60 cells.

Combined treatment with baicalin and HMBA induces the activation of caspase-3, -8 and -9 . The caspase family of cysteinyl-proteases plays the key role in the initiation and execution of programmed cell death (31). Thus, the mRNA expression of caspase-8, caspase- 9 was first detected by semiquantitative RT-PCR. As shown in Fig. 5A, baicalin treatment alone caused a $2.82 \pm 0.13$-fold and 2.29 \pm 0.11 -fold increase at the transcriptional level of caspase- 8 and caspase- 9 , respectively, as compared with the control group. When combined with HMBA, the mRNA 
A
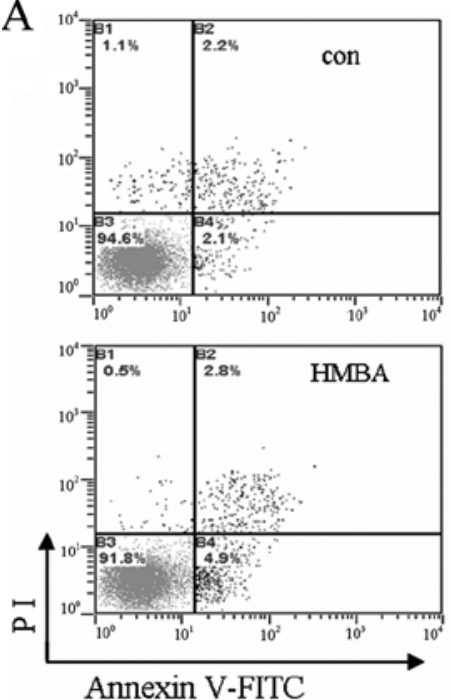
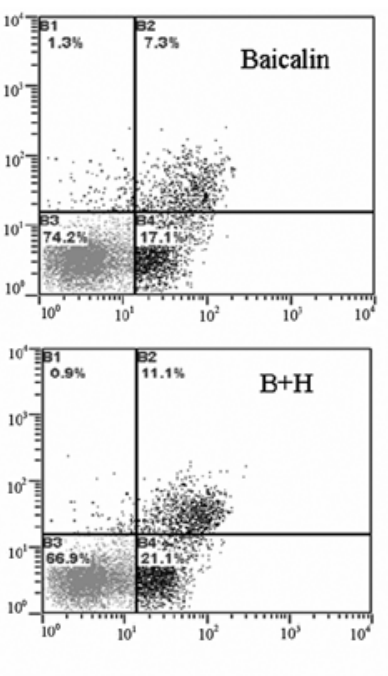

B

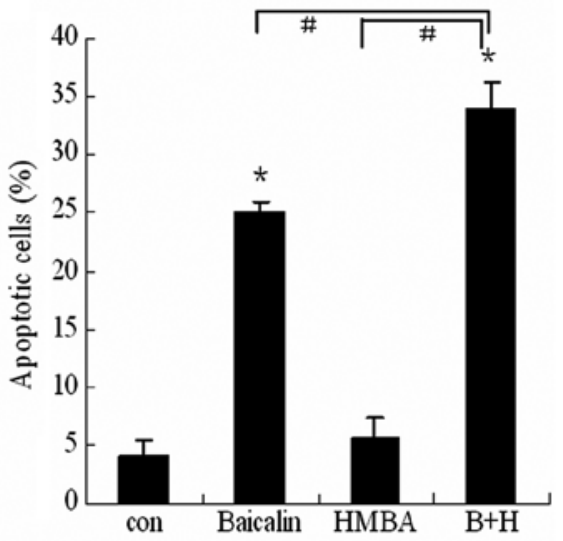

Figure 4. Apoptosis assessment by Annexin V/propidium iodide (PI) in HL-60 cells. (A) HL-60 cells were treated with $20 \mu \mathrm{g} / \mathrm{ml}$ baicalin and/or $2 \mathrm{mM}$ hexamethylene bisacetamide (HMBA) for $24 \mathrm{~h}$, stained with Annexin V and PI, and then analyzed by flow cytometry. Cells in the lower right quadrant (Annexin $\mathrm{V}^{+} / \mathrm{PI}$ ) correspond to early apoptotic cells, whereas cells appearing in the right upper quadrant $\left(\right.$ Annexin $\mathrm{V}^{+} / \mathrm{PI}^{+}$) correspond to late apoptotic cells (B) Early and late apoptotic percentages from dot plots were combined to estimate total apoptosis. Values represent the means \pm SD of a triplicate experiment. "P $<0.01$ vs. control, ${ }^{,} \mathrm{P}<0.01$ combined treatment vs. baicalin or HMBA alone.

A

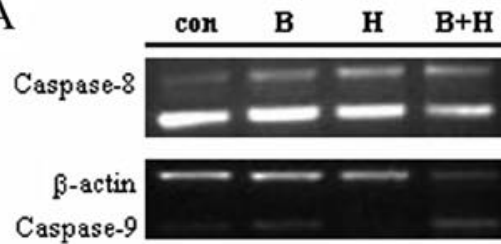

B

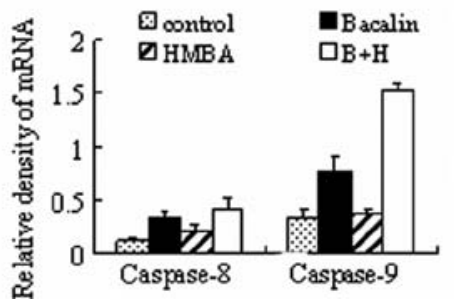

$\mathrm{C}$

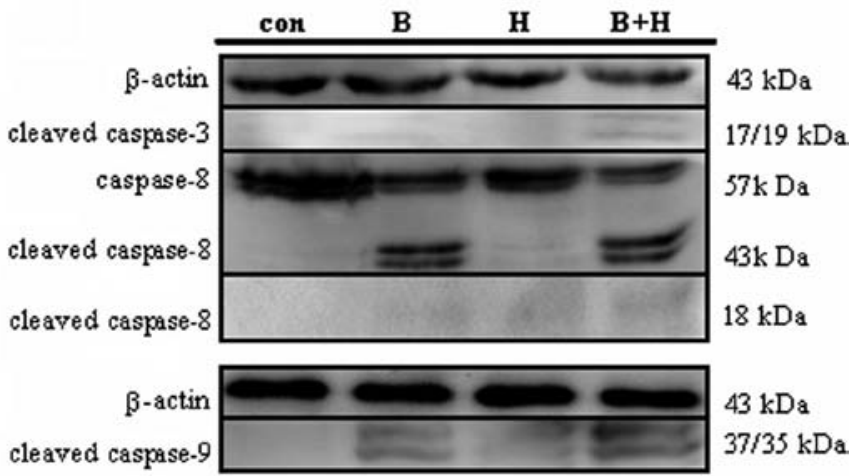

Figure 5. Effect of combined treatment with baicalin and hexamethylene bisacetamide (HMBA) on the expression of the caspase family. (A) HL-60 cells were treated with baicalin and HMBA alone or in combination for $24 \mathrm{~h}$, and the mRNA expression of caspase- 8 and caspase- 9 was then detected by reverse transcription-PCR. (B) The results were quantified by computer-aid densitometry. (C) The cell lysates were subjected to western blot analysis to determine protein level of caspase-8, caspase-9, cleaved caspase-3. $\beta$-actin was used as the loading control. Three independent studies yielded equivalent results and representative blots are shown.

expression of caspase- 8 , caspase- 9 rose to $3.43 \pm 0.10$-fold and $4.48 \pm 0.26$-fold, respectively. These data suggest that caspase- 8 and caspase- 9 may be involved in the apoptosis induced by baicalin/HMBA. To further confirm the involvement of caspases, activation of caspase- $8,-9$ and -3 was monitored by western blotting. As shown in Fig. 5B, $24 \mathrm{~h}$ exposure to $2 \mathrm{mM}$ HMBA failed to increase cleavage and activation of caspase- 3 while $20 \mu \mathrm{g} / \mathrm{ml}$ baicalin did. Moreover, combined treatment led to a clear increase in caspase-3 activation which was reflected by the appearance of a $17 \mathrm{kDa}$ caspase-3 cleavage fragment. Similarly, the cleavages of caspase- 8 and -9 were significantly enhanced by combined treatment of baicalin and HMBA. These results from RT-PCR and western blot analyses taken together thus indicate that baicalin/HMBA-induced apoptosis is mediated through the activation of caspase- $3,-8$, and -9 .
Combined treatment-induced apoptosis is mediated through both the mitochondrial-and Fas-mediated pathways. Since combination treatment induced the activation of caspase- 8 and -9 , it suggests that both extrinsic and intrinsic pathways are involved in the apoptosis signaling. To address the intrinsic pathway, $\Delta \Psi \mathrm{m}$ was monitored by flow cytometry using Rh123. The reduction of Rh123 fluorescence intensity presented dissipation of $\Delta \Psi \mathrm{m}$. As shown in Fig. 6A, HMBA administered alone for $6 \mathrm{~h}$ had little effect on $\Delta \Psi \mathrm{m}$ compared with controls, whereas baicalin alone led to a slight reduction of $\Delta \Psi \mathrm{m}$. However, combined treatment of HL-60 cells to baicalin/ HMBA resulted in a marked increase in loss of $\Delta \Psi \mathrm{m}$, as compared with either agent alone. These findings were consistent with the activation of caspase- 9 , which is often the result of disruption of $\Delta \Psi \mathrm{m}$. 

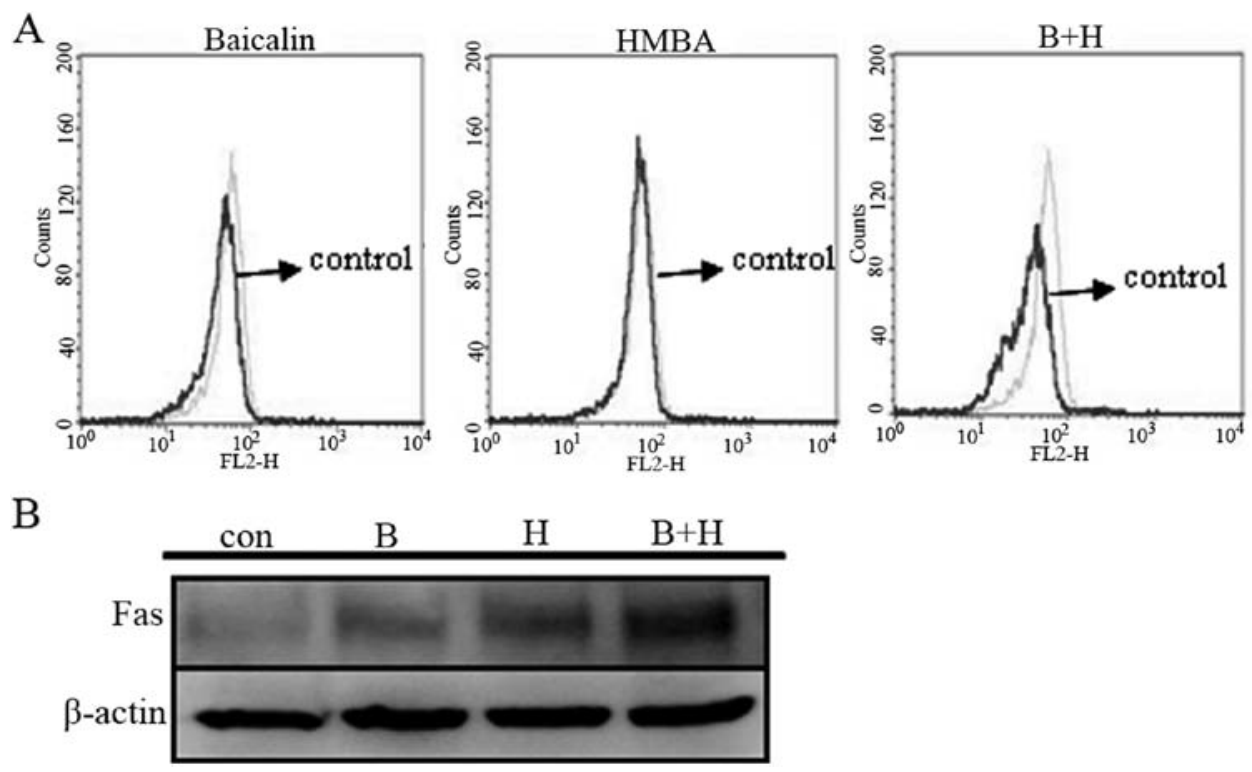

Figure 6. Effect of baicalin/hexamethylene bisacetamide (HMBA) on the change of mitochondrial membrane potential $(\Delta \Psi \mathrm{m})$ and expression of Fas protein. (A) After treating with baicalin and HMBA alone or in combination for $6 \mathrm{~h}, \mathrm{HL}-60$ cells were stained with Rho123, followed by flow cytometric analysis. The black curve presents the fluorescence intensity control group. (B) The cell lysates were subjected to western blotting to determine protein level of Fas. $\beta$-actin was used as the loading control. Three independent studies yielded equivalent results and representative blots are shown.

A
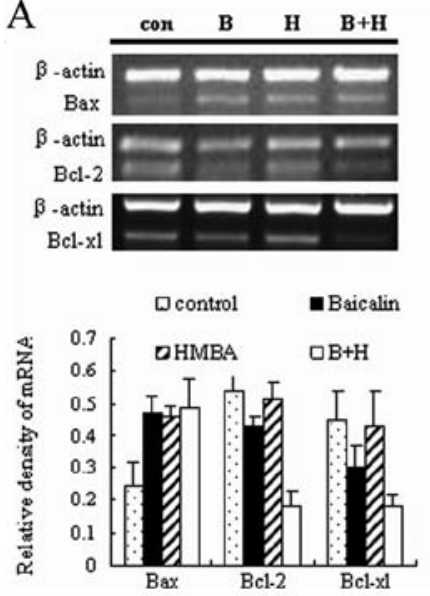
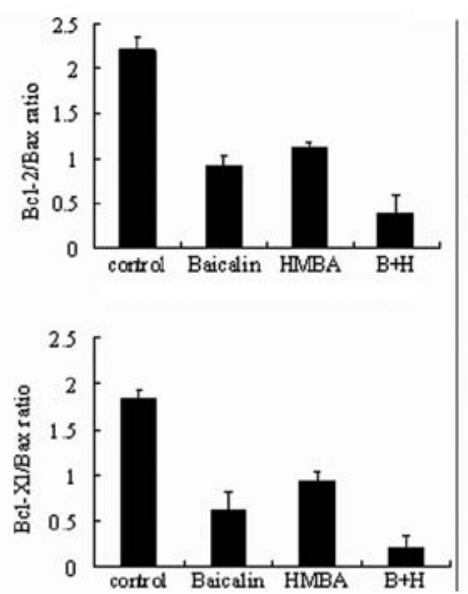
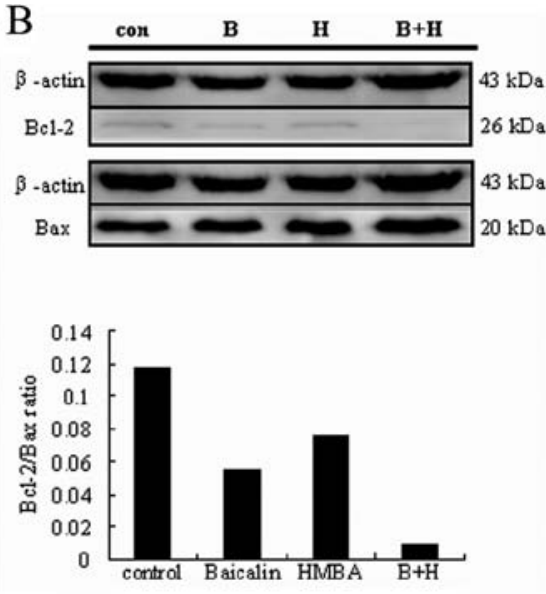

Figure 7. Effect of combined treatment with baicalin and hexamethylene bisacetamide (HMBA) on the expression of the Bcl-2 family gene. (A) HL-60 cells were treated with baicalin and HMBA alone or in combination for $24 \mathrm{~h}$ and the mRNA expression of Bax, Bcl-2, Bcl-X $\mathrm{X}_{\mathrm{L}}$ was then detected by RT-PCR. Each amplification was performed at least three times. Semi-quantitative analysis was performed using the Image J Software program. The ratio of Bcl-2/Bax and the ratio of $\mathrm{Bcl}-\mathrm{X}_{\mathrm{L}} / \mathrm{Bax}$ were calculated and presented. (B) The cell lysates were subjected to western blotting to determine protein level of Bax, Bcl-2. $\beta$-actin was used as the loading control. Three independent studies yielded equivalent results and representative blots are shown. The histogram represents ratio of values of Bcl-2/Bax.

To characterize the role of the extrinsic pathway in baicalin/ HMBA-induced apoptosis, we detected Fas protein expression by western blot analysis. The results showed that exposure to baicalin or HMBA alone triggered the Fas expression. Moreover, combination treatment significantly increased its expression (Fig. 6B). The data presented herein suggest that activation of the extrinsic Fas-related pathway plays a major role in the enhanced apoptosis observed in baicalin/HMBA-treated cells.

\section{Effect of baicalin and HMBA combined treatment on the $m R N A$} and protein expression of the Bcl-2 family. Proapoptotic and antiapoptotic members of the $\mathrm{Bcl}-2$ family regulate the mitochondrial pathway (32). To further determine whether baicalin/
HMBA-induced apoptosis in HL-60 cells is associated with the mitochondrial pathway, the expression of proapoptotic factor Bax, as well as antiapoptotic factor Bcl-2 and Bcl- $\mathrm{X}_{\mathrm{L}}$, were tested at the transcriptional and post-transcriptional level. As shown in Fig. 7A, $24 \mathrm{~h}$ exposure to either $20 \mu \mathrm{g} / \mathrm{ml}$ baicalin or $2 \mathrm{mM}$ HMBA upregulated the expression of Bax mRNA, while no evident augmentation was observed in the combination group as compared with single agent. In contrast to the increase in the Bax mRNA levels, the mRNA expression of $\mathrm{Bcl}-2$ and $\mathrm{Bcl}-\mathrm{X}_{\mathrm{L}}$ decreased more clearly in combinationtreated cells than in single agent-treated cells. Consequently, the ratio of $\mathrm{Bcl}-2 / \mathrm{Bax}$ and the ratio of $\mathrm{Bcl}-\mathrm{X}_{\mathrm{L}} / \mathrm{Bax}$ markedly declined. In parallel studies, western blot analysis revealed 
that the protein expression of Bax and Bcl-2 changed in line with the mRNA expression (Fig. 7B).

\section{Discussion}

Similar to previous findings observed in leukemic cells treated with FP in combination with SAHA $(26,27)$, the present study highlighted the synergistic antileukemic effect of baicalin in combination with HMBA in AML cell lines. It was demonstrated for the first time that the administration of a subtoxic concentration of baicalin and a pharmacologically relevant concentration of HMBA results in a synergistic effect in growth inhibition with only slight toxic effect on normal human cells.

To determine whether the synergistic inhibitory effect of the combined treatment of HL-60 cells with baicalin and HMBA is associated with the cell cycle arrest, we performed the cell cycle analysis by flow cytometry. Cell cycle analysis was studied in the way of time course as in our previous study (20), the data confirmed that HMBA alone clearly induced $\mathrm{G}_{0} / \mathrm{G}_{1}$ cell cycle arrest after treatment for $48 \mathrm{~h}$ or later. Ikezoe et al (33) reported that baicalin arrested $\mathrm{G}_{2} / \mathrm{M}$ phase in HL-60 cells; however, our results showed that baicalin induced $\mathrm{G}_{0} / \mathrm{G}_{1}$ arrest $48 \mathrm{~h}$ later. By contrast, a 24-h exposure to $2 \mathrm{mM}$ HMBA or $20 \mu \mathrm{g} / \mathrm{ml}$ baicalin alone had almost no effect on cell cycle distribution, while they could slightly induce $G_{0} / G_{1}$ arrest, which may at least partly contribute to the synergistical inhibition of cell proliferation (Fig. 2). In general, Cdk inhibitors, including p2 $1^{\text {wafl }}$ and p2 $7^{\mathrm{kipl}}$, are involved in $\mathrm{G}_{1}$ to $\mathrm{S}$ transition (34). Previous studies demonstrated that baicalin induced expression of p27 $7^{\mathrm{kip} 1}$ as well as slightly upregulated the expression of $\mathrm{p} 21^{\text {waf } 1}$ in HL-60 cells and concomitantly induced differentiation, cell cycle arrest and apoptosis in these cells (33). Buonamici and Aifantis (35) found p21 is also involved in HMBA-induced apoptosis and a short delay in cell cycle. Consistent with the above mentioned studies, herein we also found the upregulation of p21 and p27 in HMBA- or baicalin-treated cells, even more evidently with combination treatment, which may account for the $\mathrm{G}_{0} / \mathrm{G}_{1}$ cell cycle arrest (data not shown). However, the result of cell cycle distribution is not fully consistent with the synergistic growth inhibition detected by CCK- 8 assay, suggesting that other mechanisms must exist which associate with the antiproliferative effect of drugs in combination.

To confirm whether the synergistic effect on cell growth arrest is associated with apoptosis, cell morphology and Annexin V/PI staining assay were performed. Data showed that treatment of HMBA alone at a concentration of $2 \mathrm{mM}$ had almost no effect on the apoptosis of HL-60 cells. While treatment with baicalin alone induced significant apoptosis. However, the combination treatment of baicalin and HMBA induced more apoptotic cells, which suggested that HMBA may enhance the apoptosis induced by baicalin. This phenomenon is consistent with the pronounced inhibition of cell proliferation (Figs. 3 and 4).

To further delineate the convergence in apoptosis signaling, the caspases, proapoptotic and antiapoptotic proteins were detected in cells with combined treatment of baicalin and HMBA. It is well known that two major apoptotic pathways exist in mammalian cells: the extrinsic death receptor pathway and the intrinsic mitochondrial pathway (36). In the death receptor (extrinsic) pathway, binding of death ligands such as Fas ligand or TNF- $\alpha$ to their cognate death receptors triggers receptor trimerization, recruitment of the adaptor molecule FADD and caspase- 8 to the death-inducing signaling complex (DISC). This, in turn, leads to activation of caspase-8, which then either directly cleaves and activates the effector caspase-3 and -7 or cleaves Bid, a Bcl-2 family protein with a $\mathrm{BH} 3$ domain only that translocates to mitochondria upon cleavage to initiate a mitochondrial pathway (37). In the mitochondrial (intrinsic) pathway, a variety of extra- and intracellular stresses, including oxidative stress, DNA damage, heat shock and treatment with cytotoxic drugs, converge to induce the release of cytochrome $c$ from the mitochondrial intermembrane space to the cytosol. Cytochrome $c$ cooperates with dATP and Apaf- 1 to induce the activation of caspase- 9 that can cleave and activate caspase-3 (31), culminating in cell death. Previous studies demonstrated that baicalin acted as a pro-oxidant and induced caspase-3 activation and apoptosis in Jurkat cells (18) or HL-60 cells (15) via the mitochondrial pathway. Recently, the intrinsic (mitochondrial) pathway was confirmed to play a pivotal role in apoptosis induced by baicalin in CA46 Burkitt lymphoma cells (38). Consistent with previous reports, we also observed increase of caspase- 3 in cleaved form and caspase- 9 mRNA expression in HL-60 cells after exposure to baicalin for $24 \mathrm{~h}$, concomitant with the loss of $\Delta \Psi \mathrm{m}$. Furthermore, 2 mM HMBA failed to induce activation of caspase- 9 and -3 , although HMBA can do so in P-glycoprotein cells at concentrations as high as $10 \mathrm{mmol} / \mathrm{l}$ (23). However, coadministration of baicalin with HMBA resulted in enhanced dissipation of $\Delta \Psi \mathrm{m}$ and increased activation of caspase-9, caspase-3 (Figs. 5 and 6A). The data suggested that HMBA lowers the threshold for baicalin-mediated mitochondrial injury and subsequent activation of the caspase cascade, increasing the apoptotic effects induced by baicalin.

The Bcl-2 family proteins are well known for regulating the intrinsic pathway of apoptosis through tightly regulating mitochondrial outer membrane permeabilization (MOMP), which leads to the loss of $\Delta \Psi \mathrm{m}$ and therefore the release of proapoptotic molecules, including cytochrome $c$ from mitochondria to the cytosol (39). The family consists of antiapoptotic proteins, such as Bcl-2 and Bcl- $\mathrm{X}_{\mathrm{L}}$, as well as proapoptotic members, such as Bax, Bid, Bax and Bak. Accumulating evidence suggests that it is the relative ratio of antiapoptotic and proapoptotic $\mathrm{Bcl}-2$ family proteins rather than the levels of individual proteins that play a major role in determining the survival or death of cells (40). Consistent with previous reports, our data indicated that either baicalin or HMBA induced negative modulation expression of $\mathrm{Bcl}-2 / \mathrm{Bax}$ and $\mathrm{Bcl}-\mathrm{X}_{\mathrm{L}} / \mathrm{Bax}$ ratios. Moreover, the ratios decreased more significantly with combination treatment (Fig. 7). Our data suggested that HMBA at a concentration not sufficient to induce cell death per se, reduced the ratio between antiapoptotic and proapoptotic Bcl-2 family members, thereby lowering the threshold for cell death commitment and sensitizing HL-60 cells to the apoptosis induced death by baicalin. This finding is supported by Palumbo et al (24). Collectively, the modification of $\mathrm{Bcl}-2$ family proteins further indicated that the intrinsic apoptotic pathway is involved in baicalin/HMBAinduced apoptosis.

Previous studies had not referred to the effect of baicalin on change of caspase- 8 protein. In the present study, RT-PCR 
and western blot analyses results showed for the first time that the cleavage/activation of caspase- 8 increased after exposure to baicalin for $24 \mathrm{~h}$, more significantly in the combination treatment group for $24 \mathrm{~h}$ (Fig. 5), which may partly contribute to the increase of caspase- 3 activation. Consistent with the above findings, our data also showed that baicalin upregulated the expression of Fas protein (Fig. 6B). However, this is contrary to another report indicating that baicalin had no effect on the expression of Fas protein in TALL cell lines CCRF-CEM (16). The difference is likely due to the specific cell type. Moreover, baicalin markedly elevated the expression of Fas in combination with HMBA. Taking into account the pronounced upregulation of Fas expression and increased activation of caspase- 8 , we postulate that the extrinsic pathway is likely to be involved in baicalin/HMBA-induced apoptosis in HL-60 cells.

In summary, we showed that the combination of baicalin and HMBA could synergistically inhibit the proliferation of AML cell lines with little toxic effect on normal human cells. In addition, a slight $\mathrm{G}_{0} / \mathrm{G}_{1}$ phase arrest and significant apoptosis were observed. The combination treatment triggers apoptosis through the intrinsic pathway, which involves loss of MMP, decreased $\mathrm{Bcl}-2 / \mathrm{Bax}$ ratio and $\mathrm{Bcl}-\mathrm{X}_{\mathrm{L}} / \mathrm{Bax}$ ratio, caspase-9 activation, as well as through the extrinsic pathway mediated by Fas and caspase- 8 activation. Our results raise the possibility that the novel combination of baicalin and HMBA may be a promising regimen for the treatment of AML.

\section{Acknowledgements}

The authors thank Dr Guihai Li (Shandong Academy of Chinese Medicine) for providing purified baicalin and Dr Dongdong $\mathrm{Yu}$ and Lingzhi Huang for revising the manuscript. This study was supported by grants from the Natural Science Foundation of Shandong Province of China (ZR2011HL045, Y2008C165), the Youth Fund Project of the Health Department of Shandong Province (2007QZ023), and the Science and Technology Development Grant of the State Administration of Traditional Chinese Medicine of Shandong Province (2011-234), the Project of Scientific Research of Shandong Province (2007GG2002023).

\section{References}

1. Smith M, Barnett M, Bassan R, Gatta G, Tondini C and Kern W: Adult acute myeloid leukaemia. Crit Rev Oncol Hematol 50: 197-222, 2004

2. Kumar CC: Genetic abnormalities and challenges in the treatment of acute myeloid leukemia. Genes Cancer 2: 95-107, 2011.

3. Tallman MS, Gilliland DG and Rowe JM: Drug therapy for acute myeloid leukemia. Blood 106: 1154-1163, 2005.

4. Estey E and Döhner H: Acute myeloid leukaemia. Lancet 368 1894-1907, 2006.

5. Kantarjian H, O'brien S, Cortes J, et al: Results of intensive chemotherapy in 998 patients age 65 years or older with acute myeloid leukemia or high-risk myelodysplastic syndrome: predictive prognostic models for outcome. Cancer 106: 1090-1098, 2006.

6. Luo CY, Tang JY and Wang YP: Homoharringtonine: a new treatment option for myeloid leukemia. Hematology 9: 259-270, 2004.

7. Shen ZX, Chen GQ, Ni JH, et al: Use of arsenic trioxide (As2O3) in the treatment of acute promyelocytic leukemia (APL): II. Clinical efficacy and pharmacokinetics in relapsed patients. Blood 89: 3354-3360, 1997.
8. Lichtman SM, Hollis D, Miller AA, et al: Prospective evaluation of the relationship of patient age and paclitaxel clinical pharmacology: Cancer and Leukemia Group B (CALGB 9762). J Clin Oncol 24: 1846-1851, 2006

9. Zhou GB, Zhang J, Wang ZY, Chen SJ and Chen Z: Treatment of acute promyelocytic leukaemia with all-trans retinoic acid and arsenic trioxide: a paradigm of synergistic molecular targeting therapy. Philos Trans R Soc Lond B Biol Sci 362: 959-971, 2007.

10. Shen ZX, Shi ZZ, Fang J, et al: All-trans retinoic acid As2O3 combination yields a high quality remission and survival in newly diagnosed acute promyelocytic leukemia. Proc Natl Acad Sci USA 101: 5328-5335, 2004.

11. Zhao Y, Cui Z and Zhang L: Effects of icariin on the differentiation of HL-60 cells. Zhonghua Zhong Liu Za Zhi 19: 53-55, 1997 (In Chinese).

12. Ren X, Li CL, Wang HX, Wen PE, Yuan CJ, Li YM and Jiang GS: Molecular mechanism of HL-60 cells apoptosis induced by baicalin. Zhongguo Shi Yan Xue Ye Xue Za Zhi 20: 847-851, 2012 (In Chinese).

13. Huang WH, Lee AR and Yang $\mathrm{CH}$ : Antioxidative and anti-inflammatory activities of polyhydroxy flavonoids of Scutellaria baicalensis GEORGI. Biosci Biotechnol Biochem 70: 2371-2380, 2006.

14. Shang X, He X, Li M, Zhang R, Fan P, Zhang Q and Jia Z: The genus Scutellaria an ethnopharmacological and phytochemical review. J Ethnopharmacol 128: 279-313, 2010.

15. Lu HF, Hsueh SC, Ho YT, et al: ROS mediates baicalin-induced apoptosis in human promyelocytic leukemia HL-60 cells through the expression of the Gadd153 and mitochondrial-depedent pathway. Anticancer Res 27: 117-125, 2007.

16. Shieh DE, Cheng HY, Yen MH, Chiang LC and Lin CC: Baicalin-induced apoptosis is mediated by Bcl-2-dependent, but not p53-dependent, pathway in human leukemia cell lines. Am J Chin Med 34: 245-261, 2006

17. Parajuli P, Joshee N, Rimando AM, Mittal S and Yadav AK: In vitro antitumor mechanisms of various Scutellaria extracts and constituent flavonoids. Planta Med 75: 41-48, 2009.

18. Ueda S, Nakamura H, Masutani H, Sasada T, Takabayashi A, Yamaoka Y and Yodoi J: Baicalin induces apoptosis via mitochondrial pathway as prooxidant. Mol Immunol 38: 781-791, 2002.

19. Andreeff M, Stone R, Michaeli J, et al: Hexamethylene bisacetamide in myelodysplastic syndrome and acute myelogenous leukemia: a phase II clinical trial with a differentiation-inducing agent. Blood 80: 2604-2609, 1992.

20. Ren X, Wen PE, Yang WH, et al: Molecular mechanism underlying differentiation of HL-60 cells induced by hexamethylene bisacetamide. Zhongguo Shi Yan Xue Ye Xue Za Zhi 16: 1030-1034, 2008 (In Chinese).

21. Marks PA, Richon VM, Kiyokawa $H$ and Rifkind RA: Inducing differentiation of transformed cells with hybrid polar compounds: a cell cycle-dependent process. Proc Natl Acad Sci USA 91: 10251-10254, 1994.

22. Cecchinato V, Erba E, Basile A, et al: Hexamethylene bisacetamide inhibits malignant phenotype in T-ALL cell lines. Leuk Res 32: 791-797, 2008.

23. Ruefli AA, Smyth MJ and Johnstone RW: HMBA induces activation of a caspase-independent cell death pathway to overcome P-glycoprotein-mediated multidrug resistance. Blood 95: 2378-2385, 2000.

24. Palumbo C, Albonici L, Bei R, Bocci C, Scarpa S, Di Nardo P and Modesti A: HMBA induces cell death and potentiates doxorubicin toxicity in malignant mesothelioma cells. Cancer Chemother Pharmacol 54: 398-406, 2004.

25. Waxman S, Scher BM, Hellinger N and Scher W: Combination cytotoxic- differentiation therapy of mouse ery throleukemia cells with 5-fluorouracil and hexamethylene bisacetamide. Cancer Res 50: 3878-3887, 1990.

26. Almenara J, Rosato R and Grant S: Synergistic induction of mitochondrial damage and apoptosis in human leukemia cells by flavopiridol and the histone deacetylase inhibitor suberoylanilide hydroxamic acid (SAHA). Leukemia 16: 1331-1343, 2002.

27. Dasmahapatra G, Almenara J and Grant S: Flavopiridol and histone deacetylase inhibitors promote mitochondrial injury and cell death in human leukemia cells that overexpress Bcl-2. Mol Pharmacol 69: 288-298, 2006.

28. Liu J, Bi G, Wen P, et al: Down-regulation of CD44 contributes to the differentiation of HL-60 cells induced by ATRA or HMBA. Cell Mol Immunol 4: 59-63, 2007. 
29. Smith KM, Ketchart W, Zhou X, Montano MM and Xu Y: Determination of hexamethylene bisacetamide, an antineoplastic compound in mouse and human plasma by LC-MS/MS. J Chromatogr B Analyt Technol Biomed Life Sci 879: 2206-2212, 2011.

30. Conley BA, Egorin MJ, Sinibaldi V, et al: Approaches to optimal dosing of hexamethylene bisacetamide. Cancer Chemother Pharmacol 31: 37-45, 1992.

31. Ghavami S, Hashemi M, Ande SR, et al: Apoptosis and cancer: mutations within caspase genes. J Med Genet 46: 497-510, 2009.

32. Zimmermann KC, Bonzon $\mathrm{C}$ and Green DR: The machinery of programmed cell death. Pharmacol Ther 92: 57-70, 2001.

33. Ikezoe T, Chen SS, Heber D, Taguchi H and Koeffler HP. Baicalin is a major component of PC-SPES which inhibits the proliferation of human cancer cells via apoptosis and cell cycle arrest. Prostate 49: 285-292, 2001.

34. Steinman RA: Cell cycle regulators and hematopoiesis. Oncogene 21: 3403-3413, 2002.
35. Buonamici S and Aifantis I: Hexamethylene bisacetamide as a treatment for T-cell leukemia (T-ALL). Leuk Res 32: 689-690, 2008.

36. Riedl SJ and Shi Y: Molecular mechanisms of caspase regulation during apoptosis. Nat Rev Mol Cell Biol 5: 897-907, 2004.

37. Fulda S: Caspase-8 in cancer biology and therapy. Cancer Lett 281: 128-133, 2009.

38. Huang Y, Hu J, Zheng J, Li J, Wei T, Zheng Z and Chen Y: Down-regulation of the PI3K/Akt signaling pathway and induction of apoptosis in CA46 Burkitt lymphoma cells by baicalin. J Exp Clin Cancer Res 31: 48, 2012

39. Autret A and Martin SJ: Bcl-2 family proteins and mitochondrial fission/fusion dynamics. Cell Mol Life Sci 67: 1599-1606, 2010.

40. Reed JC, Jurgensmeier JM and Matsuyama S: Bcl-2 family proteins and mitochondria. Biochim Biophys Acta 1366: 127-137, 1998. 